\title{
A Simulation Enhanced VSM Approach for high-Mix Manufacturing Environment
}

\author{
Quan Yu, Erlend Alfnes, Håvard Gjengstø Brekken and Mats Moen Eide \\ Department of Production and Quality Engineering \\ Norwegian University of Science and Technology \\ Trondheim, Norway \\ quan.yu@ntnu.no, erlend.alfnes@ntnu.no
}

\begin{abstract}
As market requirements change, manufacturers are experiencing the transition from low-mix to high-mix production, handling a larger number of product variants to stay competitive and avoiding reduction of system performance. Value stream mapping (VSM) is a preferred method of implementing lean manufacturing principles in various industries with the aim of improving system performance. However, most applications are limited to low-mix environment. This paper combines VSM and discrete event simulation (DES) to model and improve the performance of a high-mix production system. The as-is model based on VSM is verified using current state production data. Accordingly, the simulation result shows the potential of improving system performance by implementing lean manufacturing principles, which provides a reference to the case company.
\end{abstract}

Keywords-Value stream mapping; high-mix; discrete event simulation

\section{INTRODUCTION}

The demand for standard product have dropped in many market segments since the last decade [1], and with this development, more and more companies are faced with a trend towards individualization of customer demand. Nowadays many of the enterprises that previously operated in the low-mix, highvolume industries are faced with a demand for higher product variety and changing demands. In order to sustain in an increasingly uncertain and competitive market, many companies are forced to accommodate their manufacturing systems to handle increased numbers of product variants. An increase in the product mix provided to the customers is often assumed to bring a competitive advantage, and the offering of products tailored to the specific customer requirements should result in higher sales volumes and higher prices [2]. Furthermore, manufacturers with the ability offer a large variety of products, and still respond quickly to customer orders are assumed to enjoy a competitive advantage [3].

Meanwhile, many manufacturers experience an impact on the performance of their production system either in terms of reduced resource utilization or an increase in manufacturing throughput time (TT), especially if an attempt to maintain high resource utilization are decided [4]. In addition to this trend towards more customer specific orders and new challenges introduced by this, manufacturing organizations are also under pressure to improve productivity and quality while at the same time reducing costs in order to stay competitive [5]. In the pursuit of enhancing overall performance of a production system, the implementation of lean manufacturing practices has become popular among industry actors. Further, value stream mapping (VSM) is stated to be a preferred approach for such implementations [6]. However, traditional VSM approach was primarily developed for supporting low-mix-high-volume repetitive production environments [7], and has become less adequate as complexity in the production environment investigated increases [8].

This paper presents a DES enhanced VSM approach for a high-mix manufacturing environment, which is used to test lean principles. Current value stream map is captured in a paper and pencil way in the case company. Accordingly, the flowchart of the simulation model is made and established in DES software FLEXSIM. The as-is model is validated comparing with the historical data. Furthermore, after applying lean principle, simulation results show that the mean throughput time and the standard deviation can be significantly reduced. The model can be used for improving overall production performance and reaching strategic goals.

\section{Case Study and Value Stream Mapping}

\section{A. Case Introduction}

The case company is a typical example of high-mix production. The product line consists of 36 different models. Most of these models are offered in two or three different sizes (small, medium and large), while other models are offered with two differential models. Additionally, most models are offered with specific optional accessories. Furthermore, all the products are offered with a wide selection of materials and colors. The main variety explosion takes place at the beginning of the production where the model and material are selected. All these customization options add up to a significant number of product varieties. The total variety of options for the products can be regarded as approximately 60,000 possibilities out of the first process step.

This research focuses on the most labor intensive and valueadding processes of the whole production, which include totally 10 processing steps. To be noticed, not all product models are required to pass through all 10 steps, which means there exist multiple routing possibilities with respect to product types. 


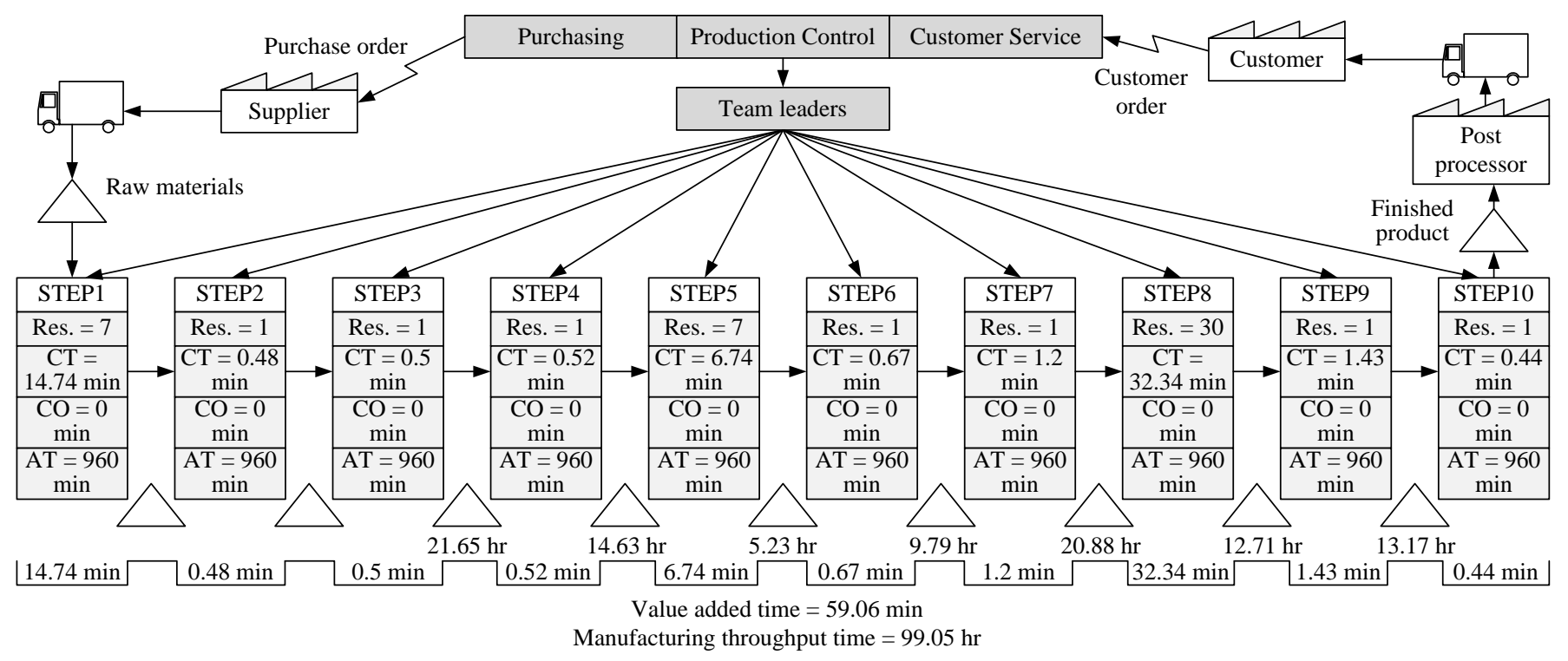

Fig. 1. Current state value stream map

\section{B. Current state VSM}

The current value stream map are shown in Fig. 1. As all products produced in selected processes mostly use the same equipment and only a few operations differ between different product models, they can in this case be regarded as one product family and should therefore be included in the same value stream map. The mapping of the product flow for the family was done by walking the flow paths and documenting with pen and paper. Moreover, the processing times was gathered from historical production data. These times were further calculated down to a weighted average, in order to represent the capacity of the specific workstation in terms of total demand, and are presented in the current state map as cycle time (CT).

In the conventional VSM, the average time in queue (WIP) and TT are calculated from multiplying the CT with the total number of products in the queue. But it is not sufficient in a highmix environment, as assigning a specific CT for the parts with highly fluctuating processing times and batch sizes can be less helpful. In order to overcome this, the inventory in front of the workstations was collected from retrieved information from the case company, with detailed waiting time spent in queue. Here, an average waiting time over a two-month period was recorded and are presented in the current state map. The waiting time in front of STEP4 are the cumulated inventory for all the previous workstations. Available time are fixed for all resources. There are no changeover times in the production line. In the production system, there are big differences in CTs and resource requirements for the different operations. Some operations never have longer than one-minute processing time, regardless of the model, while other operations vary from only a few minutes to over one hour depending on the model being processed. The operations that are required for each model vary a lot, and this result in multiple routings for the different models throughout the shop floor.

The current state map reveals several shortcomings in the production line. These are mostly related to high WIP inventories and long TTs. However, it is noticed that the highest average waiting times are located in front of STEP8, as the inventory in front of STEP4 are an average for all the previous workstations. In this case, the capacity and cycle times are of limited use in the value stream map, as these would change for different product mix variations. However, the inventories in front of the workstations imply that there are long TTs compared to the value adding time, which means that there is a great potential for TT reduction.

\section{Limitations of Traditional VSM Approach}

As pointed out by researchers, the lean methodology was initially intended for mass production (MP), characterized by low-mix, high-volume repetitive production $[9,10]$. However, it was argued that the general concept of lean can be applied in most production setting, if to some degree adapted to the specific manufacturing conditions [11]. The level of detail one can obtain from walking along the process flow, documenting value stream through the paper and pencil technique is limited [12], while this limited level of detail makes the traditional VSM approach unable to address the complexity and variability in high-mix environments. Drawbacks with the conventional VSM approach are listed below:

- Limited level of detail provides a static picture of the system investigated (paper and pencil)

- Unable to address system complexity and variability

- Guidelines for production control is based upon MP characteristics

- Does not prove feasibility or performance of potential future states

Due to the limitations of VSM and its inability to capture the complexity in production systems, DES is regarded as a promising add-on to the traditional VSM approach [6, 8], which is combined with VSM and verified to be effective in the work of reorganizing production processes and evaluation of improved production performance [11]. 


\section{VSM BASED SIMULATION}

\section{A. Lean Principle Implementation}

The purpose of the simulation study is to investigate if it is possible to implement lean principle and reduce the mean throughput time (MTT) and the variation while at the same time maintaining sufficient output levels. Altogether, four different cases were designed. Each follows the same layout, illustrating the shop floor of the investigated production system at the case company. The scenarios differ in terms of batch sizes, sequencing rules and control mechanisms, as shown in TABLE I. Three performance variables, in terms of production rate (PR), MTTs and standard deviation (STD) of MTT, are used to assess the system performance.

TABLE I. PERFORMANCE VARIABLES

\begin{tabular}{|l|c|}
\hline \multicolumn{1}{|c|}{ Performance variables } & Values \\
\hline $\begin{array}{l}\text { Production batch size } \\
\text { (variable with upper limit) }\end{array}$ & $10,5,1$ \\
\hline Sequencing rule & Priority by model family, FIFO \\
\hline Control mechanism & PUSH, CONWIP (300, 200, 100) \\
\hline
\end{tabular}

The as-is scenario is considered as a reference point, where conditions similar to those of the case company have been attempted to be replicated as far as possible. Four cases are designed to show the variation between the approaches, divided into 24 scenarios. The batch size reduction and the CONWIP levels are the only parameters that is consistently changed in the cases. All the cases are elaborated in detail below.

In case 1, the same sequence rules and control mechanisms as in the AS-IS situation was applied. The batch size reduction will be the only variable in this case.

In case 2, FIFO controlled system is applied as a sequencing rule and tested with different batch sizes.

In case 3, CONWIP is applied as a control mechanism and tested with different batch sizes.

In case 4 , Both FIFO and CONWIP for different batch sizes are simulated.

\section{B. Simulation model based on the VSM}

The simulation model was established in DES software FLEXSIM as shown in .Fig. 2 and Fig. 3.

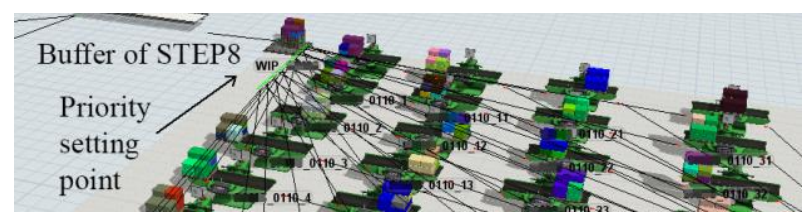

Fig. 2. Priority rules setting for STEP8

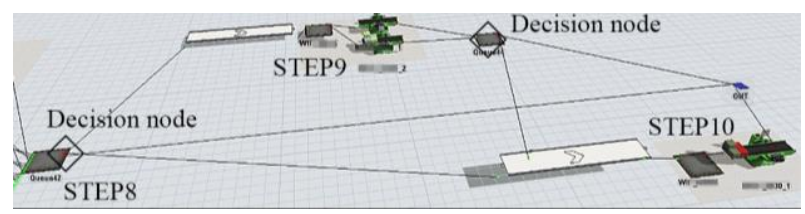

Fig. 3. Decision nodes for STEP8, STEP9 and STEP10
According to the design of lean principle implementation, a flowchart of the simulation model is established based on current VSM, as shown in Fig. 4.

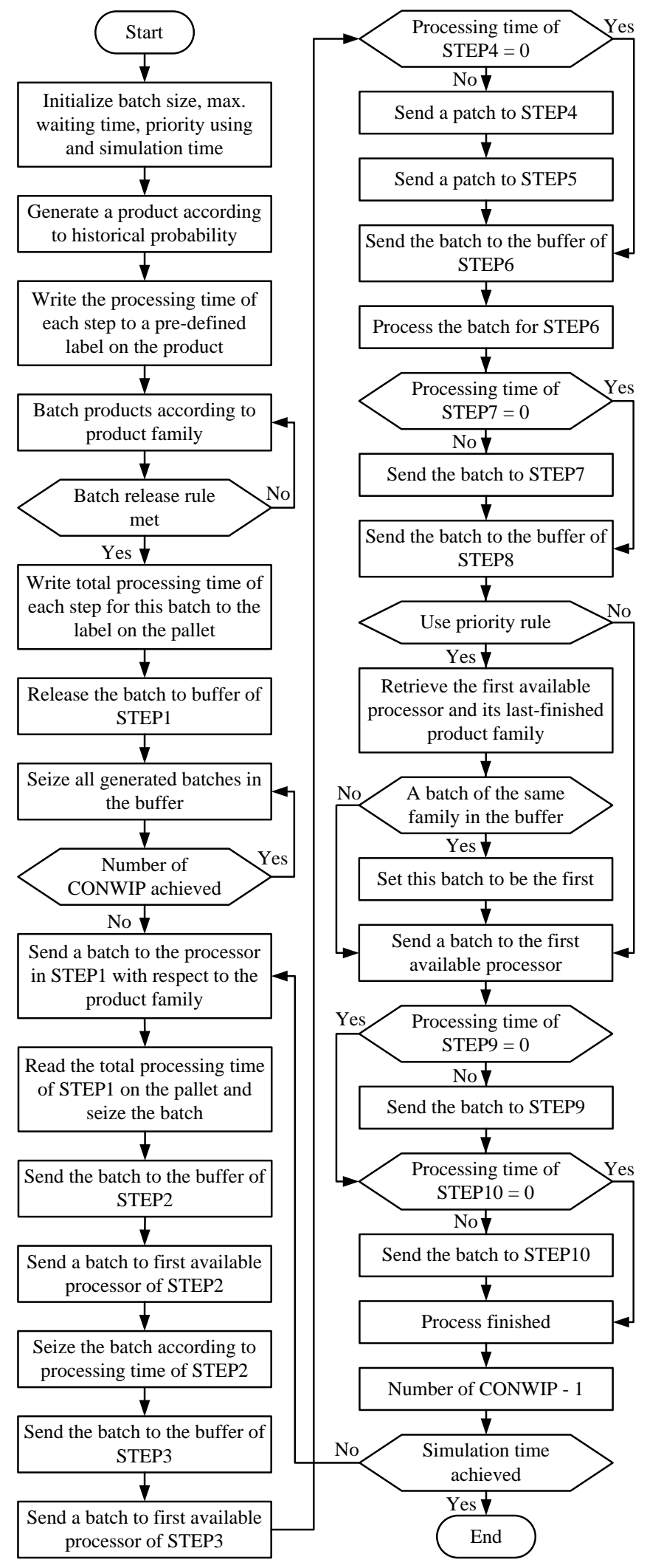

Fig. 4. Flowchart of the simulation model based on VSM 
The WIP control mechanism, priority control and decision point settings for multiple routines are the most critical to the flexibility and reliability of the simulation model.

\section{Simulation Results}

In order to increase the validation of the simulation model, the first day of simulation results was removed from the data analysis. This was done in order to make the system stabilize after the ramp up time, which will yield results that are more reliable. Simulation results are shown in TABLE II. Only typical scenarios are listed due to the page limits.

\section{TABLE II. SIMULATION RESUlTS}

\begin{tabular}{|l|l|l|l|l|l|l|l|l|}
\hline & Bat. & Seq. & Mech. & CON. & Vol. & PR & MTT & STD \\
\hline AS-IS & 10 & PRI & P & INF & 16207 & 53.31 & 1401.6 & 996.4 \\
\hline Case2 & 5 & FIFO & P & INF & 16995 & 55.90 & 1082.9 & 551.9 \\
\hline Case3 & 5 & PRI & C & 100 & 16117 & 53.02 & 509.5 & 370.8 \\
\hline Case4 & 5 & FIFO & C & 200 & 17094 & 56.23 & 848.3 & 363.4 \\
\hline Case4 & 5 & FIFO & C & 100 & 16279 & 53.55 & 508.8 & 318.3 \\
\hline Case4 & 1 & FIFO & C & 100 & 11426 & 37.59 & 156.4 & 172.8 \\
\hline
\end{tabular}

The as-is situation were attempted replicated, with batch sizes of 10 , priority based picking and a PUSH system. The STD of TT, which shows the variability, was recorded to be 996.4 minutes, or 16.61 hours, which is shorter than the value in the current state VSM. But the distribution of TT variability is similar to the historical data.

Five typical scenarios are compared with the as-is scenario. The outputs are shown in Fig. 5. It is noticed that the implementation of CONWIP can significantly reduce the TT and TT STD, without affecting the PR. However, the batch size needs to be carefully selected under this condition.

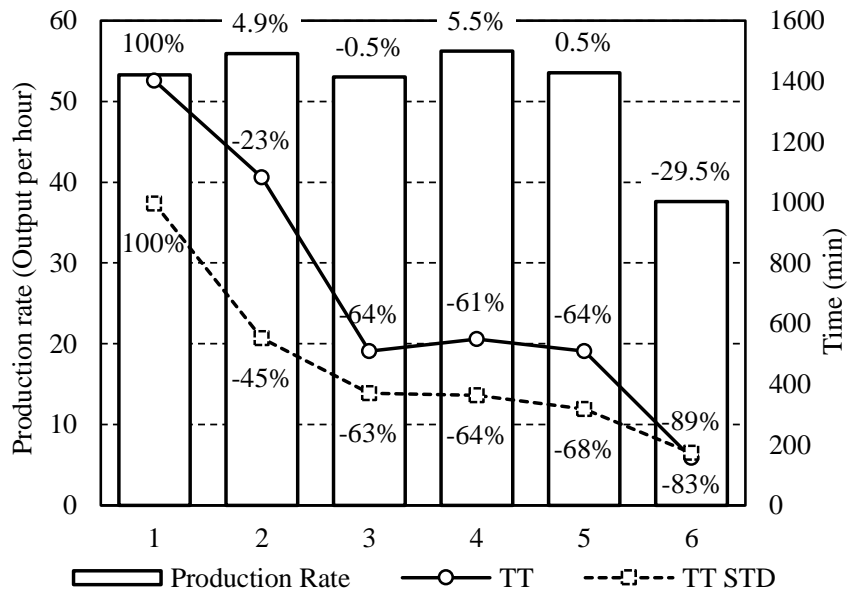

Fig. 5. Scenario comparison

\section{CONCLUSION AND DISCUSSION}

The combination of traditional VSM and simulation successfully replicate the as-is model of the current production in the case company, which is verified as a reliable foundation to simulate lean principles in the production system. The simulation results show a great potential from implementation of CONWIP and batch size control. Although the simulation model has some limitations, such as ignoring the "mental" change over time of operators, disallowing shared resources, and lacking downtime control, it still provides a valuable reference for the case company and will be improved further in the future research.

\section{ACKNOWLEDGMENT}

This research has been carried out as part of SØM4.0 project. The authors thank the partners in the project for facilitating this work.

\section{REFERENCES}

[1] E. Alfnes, and J. O. Strandhagen, "Enterprise Design for Mass Customisation: The Control Model Methodology," International Journal of Logistics Research and Applications, vol. 3, no. 2, pp. 111-125, 2000/07/01, 2000.

[2] F. Salvador, C. Forza, and M. Rungtusanatham, "Modularity, product variety, production volume, and component sourcing: theorizing beyond generic prescriptions," Journal of Operations Management, vol. 20, no. 5, pp. $549-575,9 / /, 2002$

[3] D. Gupta, and S. Benjaafar, "Make-to-order, make-to-stock, or delay product differentiation? A common framework for modeling and analysis," IIE Transactions, vol. 36, no. 6, pp. 529-546, 2004/06/01, 2004.

[4] N. Modig, and P. Åhlström, This is lean : resolving the efficiency paradox, Stockholm: Rheologica publ., 2012.

[5] G. Chauhan, and T. P. Singh, "Measuring parameters of lean manufacturing realization," Measuring Business Excellence, vol. 16, no. 3, pp. 57-71, 2012.

[6] T. McDonald, E. M. Van Aken, and A. F. Rentes, "Utilising Simulation to Enhance Value Stream Mapping: A Manufacturing Case Application," International Journal of Logistics Research and Applications, vol. 5, no. 2, pp. 213-232, 2002/07/01, 2002.

[7] D. T. Matt, "Adaptation of the value stream mapping approach to the design of lean engineer-to-order production systems: A case study," Journal of Manufacturing Technology Management, vol. 25, no. 3, pp. 334-350, 2014.

[8] D. Schmidtke, U. Heiser, and O. Hinrichsen, "A simulation-enhanced value stream mapping approach for optimisation of complex production environments," International Journal of Production Research, vol. 52, no. 20, pp. 6146-6160, 2014/10/18, 2014.

[9] E. Lander, and J. K. Liker, "The Toyota Production System and art: making highly customized and creative products the Toyota way," International Journal of Production Research, vol. 45, no. 16, pp. 36813698, 2007/08/15, 2007.

[10] J. Slomp, J. A. C. Bokhorst, and R. Germs, "A lean production control system for high-variety/low-volume environments: a case study implementation," Production Planning \& Control, vol. 20, no. 7, pp. 586595, 2009/10/01, 2009.

[11] A. Gurumurthy, and R. Kodali, "Design of lean manufacturing systems using value stream mapping with simulation: A case study," Journal of Manufacturing Technology Management, vol. 22, no. 4, pp. 444-473, 2011

[12] Y. H. Lian, and H. Van Landeghem, "Analysing the effects of Lean manufacturing using a value stream mapping-based simulation generator," International Journal of Production Research, vol. 45, no. 13, pp. 3037-3058, 2007/07/01, 2007. 